\title{
Analysis of Influence of Inertia Moment on Dynamic Characteristics of Concrete Pump Mixing System
}

\author{
Zhao Qing ${ }^{1, a}$, Liu Huiyong ${ }^{2, b \neq}$, Xiong Yeping ${ }^{3, c}$ \\ ${ }^{1}$ College of Civil Engineering, Guizhou University, Guiyang, China \\ ${ }^{2}$ School of Mechanical Engineering, Guizhou University, Guiyang, China \\ ${ }^{3}$ Faculty of Engineering and the Environment, University of Southampton, Southampton, UK \\ a75206983@qq.com, bheartext@163.com, 'Y.Xiong@soton.ac.uk
}

\begin{abstract}
Keywords: Concrete pump; Mixing system; Dynamic characteristics; Inertia moment Abstract. The aim of this paper is to analyze influence of inertia moment on dynamic characteristics of mixing system. First, the basic structure of mixing system is introduced, and the working principle of mixing system is illustrated. Second, the simulation model of mixing system is established based on AMESim according to the working principle of mixing system. Third, the influence of inertia moment on dynamic characteristics of mixing system is analyzed. The research result indicates that in the viewpoint of decreasing pressure shock and vibration, the inertia moment should be decreased as possible when designing mechanical device of mixing system. The research result provides a reference for designing mechanical device of concrete pump mixing system.
\end{abstract}

\section{Introduction}

Concrete pump is a kind of construction equipment for delivering concrete through pipes under pressure. It has been widely used in lots of construction projects including high-rise buildings, bridges, hydropower stations, etc, because of some advantages such as high efficiency, low labor density, et al[1-2]. The concrete pump mixing system is located in a hopper of concrete pump, using hydraulic pump to drive hydraulic motor and rotate the mixing rod, consequently agitate concrete in the hopper. By doing so, it can not only reduce concrete segregation, but also can improve pumpability and enhance suck efficiency [3]. The dynamic characteristics of concrete pump mixing system are to be affected by inertia moment of mixing system, therefore it is very meaningful to analyze the influence of inertia moment on the dynamic characteristics of mixing system.

In recent years, there have been some literatures contributing to design and theory of concrete pump mixing system. In [4], the general design for integrated truck mounted concrete pump and mixing mechanism was introduced, and finite element analysis of assembly of mixing blade was carried out. In [5], the design of transmission shaft of mixing system was improved. In [6], the concrete pump mixing system was introduced in detail, and the rationality as well as the superiority of two-sides-driving method was discussed in terms of force and stress distribution of mixing shaft. In [7], the working condition of original sealing structure of mixing shaft was analyzed, and the mechanical failure caused by insufficient lubrication was eliminated. In [8], the mixing circuit system of concrete pump was improved. In [9], the influence of the layout of mixing blade on the sucking performance was analyzed, and the layout of different mixing blade was designed. AMESim is an advanced modeling and simulation environment for establishing system model of multi discipline including machine, hydraulic, electric, etc. and it has been used in some fields such as wind turbine, hybrid system, construction machinery, et al [10].

The aim of this paper is to analyze the influence of inertia moment on the dynamic characteristics of mixing system, and the rest of this paper is organized as follows: In Section 2, the basic structure of mixing system is introduced, and the working principle of mixing system is illustrated. In Section 3 , the simulation model of mixing system is established. In Section 4 , the influence of inertia moment on the dynamic characteristics of mixing system is analyzed. Finally, conclusions and some future works are pointed in Section 5. 


\section{Structure of Concrete Pump Mixing System}

Concrete pump mixing system is mainly composed of hydraulic pump, relief valve, direction valve and hydraulic motor, as shown in Fig. 1. The working principle of concrete pump mixing system is as follows: Engine (5) drives hydraulic pump (4), and the pressure oil from pump (4) flows through directional control valve (3) and into hydraulic motor (2), then hydraulic motor begins to rotate and drives the mixing shaft to rotate to agitate concrete.

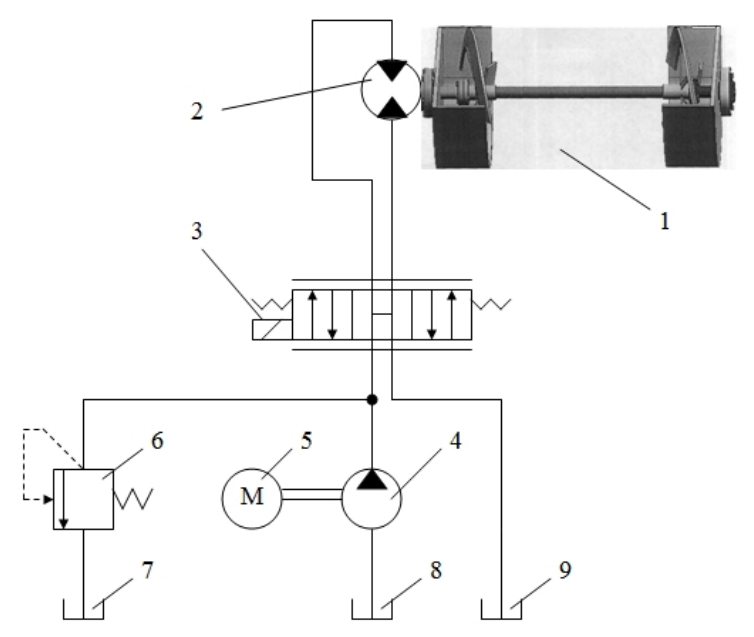

Fig. 1 Schematic diagram of concrete pump mixing system 1-mixing device 2-hydraulic motor 3-directional control valve 4-hydraulic pump 5-engine 6-relief valve 7、8、9-tank

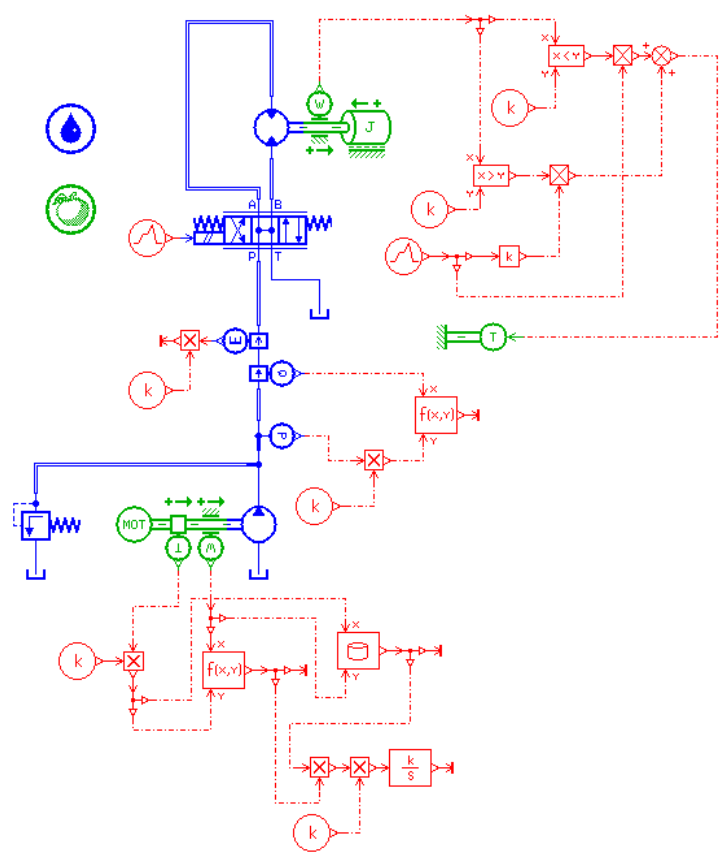

Fig. 2 Simulation model of concrete pump mixing system

\section{Model of concrete pump mixing hydraulic system}

By selecting appropriate component model in machine library, signal and control library, hydraulic library, etc. in modeling and simulation environment AMESim, the simulation model of concrete pump mixing hydraulic system can be established, as shown in Fig. 2.

\section{Analysis of influence of inertia moment on dynamic characteristics}

In this paper, the internal and dynamic characteristics of engine are neglected. The rotation speed and the displacement is $1480 \mathrm{rev} / \mathrm{min}$ and $22 \mathrm{cc} / \mathrm{rev}$, respectively. The set value of relief valve is $160 \mathrm{bar}$. The meso-position function of directional control valve is H-type. The displacement of hydraulic motor is $1000 \mathrm{cc} / \mathrm{rev}$. The time of direction change is $30 \mathrm{~s}$. The mixing load is $840 \mathrm{Nm}$. The coefficient of viscosity is $1 \mathrm{Nm}(\mathrm{rev} / \mathrm{min})$. By setting the inertia moment as $0.4235 \mathrm{~kg} \cdot \mathrm{m}^{2}, 0.847 \mathrm{~kg} \cdot \mathrm{m}^{2}$, $1.2705 \mathrm{~kg} \cdot \mathrm{m}^{2}, 1.694 \mathrm{~kg} \cdot \mathrm{m}^{2}, 2.1175^{\mathrm{kg} \cdot \mathrm{m}^{2}}$, the dynamic characteristics of mixing system include pressure, flow rate, power of mixing hydraulic system can be obtained, as shown in Fig. 3- Fig. 8.

\section{Influence of inertia moment on pressure}

It can be seen from Fig. 3 that pressure in inlet has an impact at the beginning stage. This is because pressure oil cannot change its direction as soon as possible when changing the control current of direction control valve. After a period of impact oscillation, pressure in inlet 1 is stabilized at 55bar. Fig. 4 is partial amplification of pressure in inlet of hydraulic motor. When the inertia moment is $0.4235 \mathrm{~kg} \cdot \mathrm{m}^{2}, 0.847 \mathrm{~kg} \cdot \mathrm{m}^{2}, 1.2705 \mathrm{~kg} \cdot \mathrm{m}^{2}, 1.694 \mathrm{~kg} \cdot \mathrm{m}^{2}$ and $2.1175 \mathrm{~kg} \cdot \mathrm{m}^{2}$, pressure impact degree is about $24.18 \%, 38.18 \%, 56.36 \%, 68.18 \%$ and $76.73 \%$, respectively. It can be easily seen that with the increasing of inertia moment from $0.4235 \mathrm{~kg} \cdot \mathrm{m}^{2}$ to $2.1175 \mathrm{~kg} \cdot \mathrm{m}^{2}$, pressure impact increases consequently, especially, the period of pressure impact oscillation is longer. 


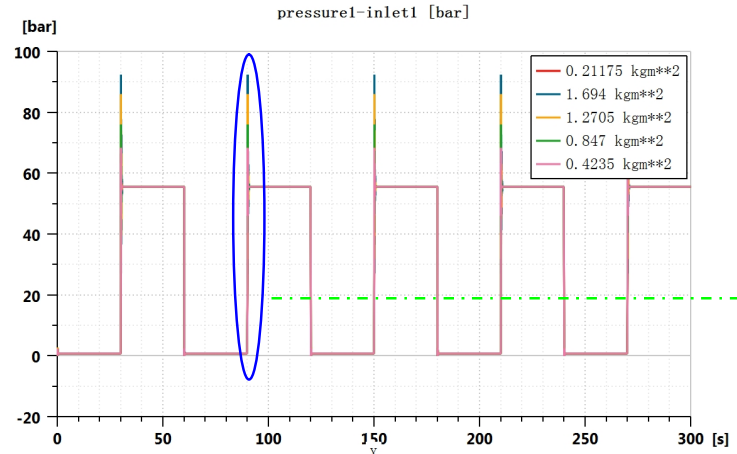

Fig. 3 Pressure in inlet 1 of hydraulic motor

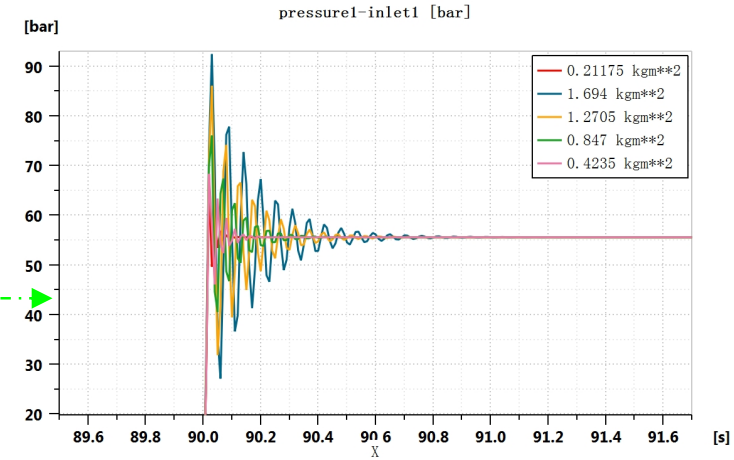

Fig. 4 Partial amplification of pressure in inlet 1 of hydraulic motor

\section{Influence of inertia moment on flow rate}

It can be seen from Fig. 5 that flow rate in inlet has an impact at the beginning stage. After a period of impact oscillation, flow rate in inlet is stabilized at $32 \mathrm{~L} / \mathrm{min}$. Fig. 6 is partial amplification of flow rate in inlet of hydraulic motor. When the inertia moment is $0.4235 \mathrm{~kg} \cdot \mathrm{m}^{2}, 0.847 \mathrm{~kg} \cdot \mathrm{m}^{2}, 1.2705 \mathrm{~kg} \cdot \mathrm{m}^{2}$, $1.694 \mathrm{~kg} \cdot \mathrm{m}^{2}$ and $2.1175 \mathrm{~kg} \cdot \mathrm{m}^{2}$, flow rate impact degree is about $71.88 \%, 59.38 \%, 81.25 \%, 79.69 \%$ and $76.56 \%$, respectively.

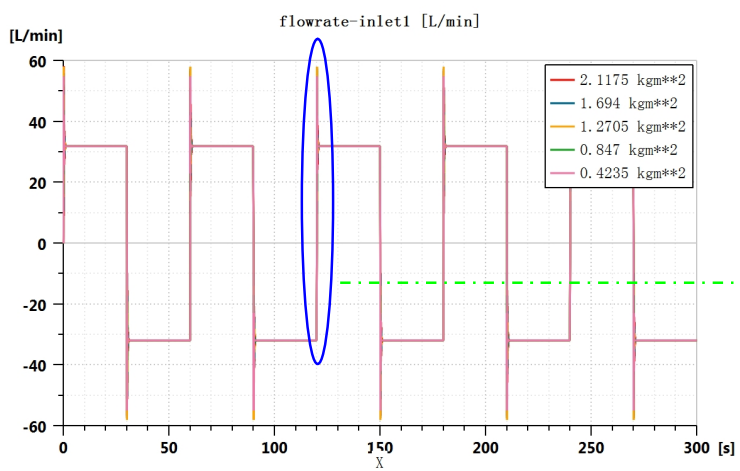

Fig. 5 Flow rate in inlet 1 of hydraulic motor

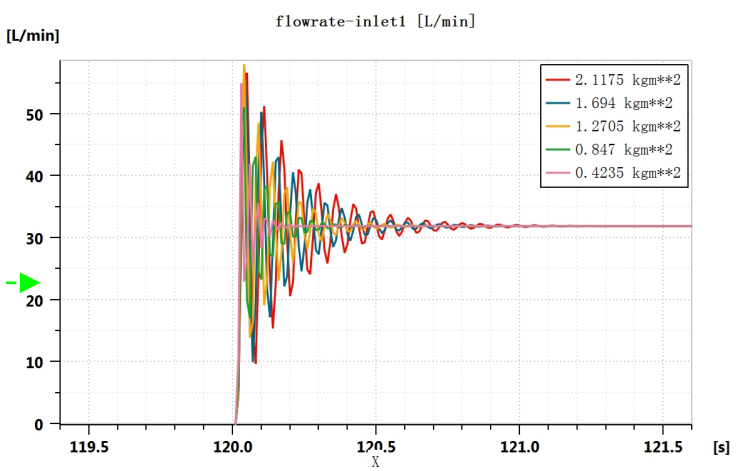

Fig. 6 Partial amplification of flow rate in inlet 1 of hydraulic motor

\section{Influence of inertia moment on power of mixing hydraulic system}

It can be seen from Fig. 7 that power of mixing hydraulic system has an impact at the beginning stage. After a period of impact oscillation, power of mixing hydraulic system is stabilized at $3 \mathrm{~kW}$. Fig. 8 is partial amplification of power of mixing hydraulic system. When the inertia moment is $0.4235 \mathrm{~kg} \cdot \mathrm{m}^{2}$, $0.847 \mathrm{~kg} \cdot \mathrm{m}^{2}, 1.2705 \mathrm{~kg} \cdot \mathrm{m}^{2}, 1.694 \mathrm{~kg} \cdot \mathrm{m}^{2}$ and $2.1175 \mathrm{~kg} \cdot \mathrm{m}^{2}$, power impact degree is about $45 \%$, $71 \%, 71.67 \%, 78 \%$ and $96.67 \%$, respectively.

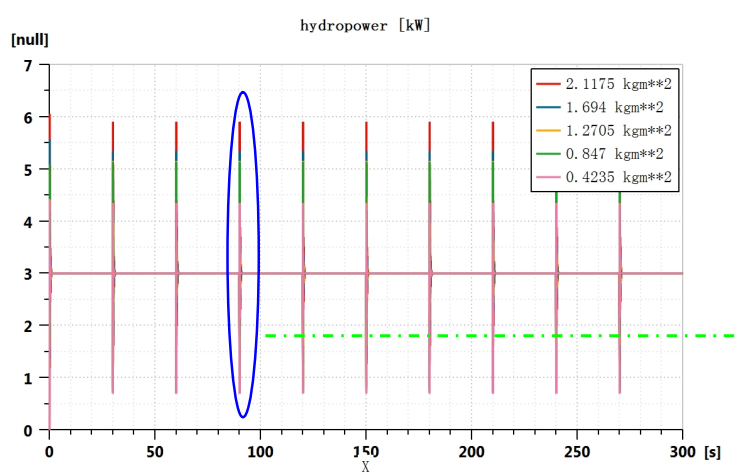

Fig. 7 Power of mixing hydraulic system

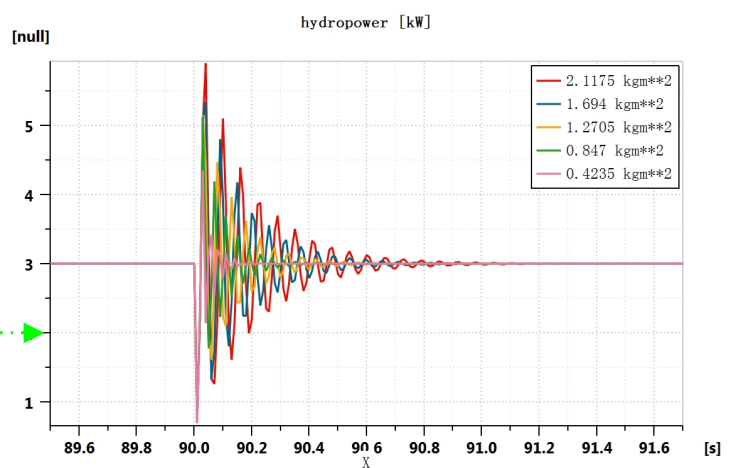

Fig. 8 Partial amplification of Power of mixing hydraulic system 


\section{Conclusions}

In order to improve the performance of concrete pump mixing system, this paper aims to analyze the influence of inertia moment on the dynamic characteristics of mixing system. First, the basic structure of mixing system is introduced, and the working principle of mixing system is illustrated. Second, the simulation model of mixing system is established based on AMESim according to the working principle of mixing system. Third, the influence of inertia moment on the dynamic characteristics of mixing system is analyzed.

When changing the mixing direction, pressure, there is impact and oscillation on flow rate, rotation speed, torque, hydraulic system power and so on will produce impact and oscillation. The research result indicates that with the increasing of inertia moment from $0.4235 \mathrm{~kg} \cdot \mathrm{m}^{2}$ to $2.1175 \mathrm{~kg} \cdot \mathrm{m}^{2}$, the time of impact and oscillation will last longer. In the viewpoint of decreasing pressure impact and oscillation, the inertia moment should be decreased as possible when designing mechanical device of mixing system. The research result provides a reference for designing mechanical device of concrete pump mixing system.

\section{Acknowledgements}

This work was financially supported by the National Natural Science Foundation of China [grant number: 51365008]; the Joint Foundation of Science and Technology Department of Guizhou Province [grant number: Qiankehe LH Zi[2015]7658] ; the Foundation of Science and Technology Department of Guizhou Province [grant number: Qiankehe J Zi[2010]2247]; The Tribology Science Fund of State Key Laboratory of Tribology [grant number: SKLTKF13B07]. The authors gratefully acknowledge their support. Additionally, Liu Huiyong acknowledges the financial support from China Scholarship Council (CSC) to visit the Fluid-Structure Interaction Research Group (FSIRG) in the Faculty of Engineering and the Environment at the University of Southampton [grant number 201606675008].

\section{References}

[1] Zhang Guozhong : Modern concrete pump truck and its application technology in construction (China Building Materials Press, China 2004)( In Chinese)

[2]LIU Huiyong, LI Wei, LIN Yonggang, GU Daqiang, SONG Ruiyin. Measuring Method of Concrete Pump Discharge Based on Pumping Pressure. JOURNAL OF MECHANICAL ENGINEERING, Vol.45(5)(2009), P.165-170( In Chinese).

[3]LIU Huiyong, LI Wei, LIN Yonggang, GU Daqiang, HUANG Qianchun, ZHAO Qing. Study on Modeling and Simulation of Concrete Pump Agitating System Based on AMESim. MACHINETOOL \& HYDRAULICS, Vol.36(5)(2008), P.165-166,153( In Chinese)

[4] ZHANG Lan-di, ZHANG Dong-hui, ZHANG Can-guo, REN Yu-can, CHEN Long. Design of Integrated Machine of Concrete Pump and Mixing Institution. Coal Technology, Vol.31(3)(2012),P.14-16( In Chinese)

[5] LENG Jian-chun, ZHONG Chuan. The improvement design of the agitation system of concrete pump of model BSA1408-E. Construction Mechanization, 1(2014) , P.37-38( In Chinese)

[6]ZHU Shan-ji, YE Xiao-han. Mixing system of PUTZMEISTER BSA1408-E trailer mounted concrete pump. Construction Mechanization, 4 (2004) , P.37-38( In Chinese)

[7]Cheng Pengfei. Improvement of Lubrication and Sealing of Mixing Shaft of HB30 Concrete Pump. Technology \& Management for Construction Machinery. 3(2000), P.40-41( In Chinese)

[8]Yuan Yizhong, Jia Xuesen, Qian Chuanwen. Improvement of mixing oil circuit system of HB30 concrete pump. Construction Machinery. 5(1983) , P.12-14( In Chinese)

[9]Fu Zhongxuan. Reasonable arrangement of mixing blades of concrete pump. Technology \& Management for Construction Machinery. Vol.10(5)(1997), P. 23-24( In Chinese) 
[10] FU Yongling and QI Xiaoye: System Modeling and Simulation Based on AMESim -- From entry to mastery (BEIHANG UNIVERSITY PRESS, China 2006) (In Chinese) 